\title{
Study on the microscopic pore structures of the four different kinds of lithological reservoirs in the basin of Western China
}

\author{
Tianqi Liu ${ }^{1,2}$ (D) Shengchun Xiong ${ }^{2} \cdot$ Jiayi Yu ${ }^{3} \cdot$ Ying He$^{2} \cdot$ Peng Song ${ }^{4} \cdot$ Shasha $\mathrm{Chu}^{2} \cdot$ Wei Lin $^{5} \cdot \mathrm{Haitao} \mathrm{Hou}^{2}$
}

Received: 15 December 2020 / Accepted: 27 February 2021 / Published online: 17 March 2021

(c) The Author(s) 2021

\begin{abstract}
In the basin of western China, four different kinds of lithological reservoirs are developed, including low-permeability sandstone, sedimentary tuff, shale and volcanic rock. There is generally a large difference in the micropore structure characteristics and distribution laws due to different reservoirs. The reserving capacity as well as the porous flowability, mechanism and laws are determined by the micropore structure characteristics and distribution laws of hydrocarbon reservoirs. Low-temperature nitrogen adsorption and desorption technology, high-pressure mercury injection experiment and nuclear magnetic resonance (NMR) testing technology are applied to study the micropore size, quantity, structure and distribution laws of four different kinds of lithological reservoirs as well as their similarities and differences of corresponding relation with macroporosity-permeability physical parameters. This paper also studies the movable fluid and nonlinear seepage flow characteristics of four different kinds of lithological reservoirs.
\end{abstract}

Keywords High-pressure mercury injection $\cdot$ Microscopic pore structure $\cdot$ Influence factors $\cdot$ Movable fluid $\cdot$ Nonlinear seepage flow

\section{Introduction}

The macroscopic porosity and permeability of the tight reservoir are fundamentally determined by the development degree of porosity in the reservoir. Reservoirs with different pore structure types correspond to different rules of oil and water seepage flow, which is also the key factor affecting the production characteristics of oil wells. In the basin of western China, there are four kinds of different reservoir lithologies: low-permeability sandstone, sedimentary tuff, shale

Tianqi Liu

ningmeng131997@163.com

1 College of Engineering Science, University of the Chinese Academy of Sciences, Beijing 100493, China

2 Institute of Percolation and Fluid Mechanics, China Petroleum Exploration and Development Research Institutes, Langfang 065007, China

3 Research Institute of Exploration and Development, Tuha Oilfield, PetroChina, Hami 839009, China

4 Research Institute of Exploration and Development, Changqing Oilfield, PetroChina, Xi' an 710018, China

5 School of Geosciences, Yangtze University, Wuhan 430100, China and volcanic rock. There are few comparative studies on the microstructure of reservoirs of different kinds of lithological reservoirs in the same area, so it is necessary to study the pore structure of different kinds of lithological reservoirs. In this paper, four different kinds of lithological reservoirs in the basin of western China are taken as examples to analyze the microscopic pore structure characteristics and movable fluid states of reservoirs, providing a basis for understanding the microscopic pore structure differences among different kinds of lithological reservoirs.

\section{Microscopic pore structures of different kinds of lithological reservoirs}

The microscopic pore structure of a core refers to the geometry, size, distribution and interconnection relationship of pores and throats of a rock (Peng 2009; Jianpeng et al. 2020; Xing et al. 2020). In-depth study of the microscopic pore structure characteristics of the reservoir is helpful to strengthen the cognition of the flow space of oil, gas and water and is also the basis for further study of the rule of fluid seepage flow. From the view of the research methods of the microscopic pore structure characteristics of reservoirs, 
they are mainly classified into two categories (Ghous 2008): experimental methods and numerical simulation methods. The experimental methods mainly include (Knackstedt 2006; Feng et al. 2013; Xiaodong et al. 2015; Zhidong et al. 2020; Hua et al. 2012; Tiening and Zhengming 2008; Cai et al. 2014,2015): capillary force curve method (conventional mercury intrusion method, semipermeable baffle plate method and centrifuge method), pore cast thin section method, adsorption method, optical method. The numerical simulation method, namely digital core technology (Keeler et al. 2013; Bin and Yanjun 2012; Liang et al. 2016; Likai et al. 2019; Difei et al. xxxx; Xiao Tenshi and Shuangfang 2019; Curtis et al. 2011). It can be used to simulate the pore size distribution and network topology structure of pores, etc. In this paper, the microscopic pore structures of four different kinds of lithological reservoirs in the basin of western China are analyzed and characterized by low-temperature nitrogen adsorption and desorption technology, high-pressure mercury injection and other physical experimental methods.

\section{Relationship between porosity and permeability of four different kinds of lithological reservoirs}

Porosity and permeability are the most basic physical parameters for reservoir evaluation. In this paper, 107 pieces of cores of four different kinds of lithological reservoirs are taken from the study area for testing porosity and permeability. The test method is based on GB/T 29172-2012 Core Analysis Method, and the test results are shown in Table 1.

It can be indicated from the table that the physical properties of four different kinds of lithological reservoirs are greatly different. Sedimentary tuff has relatively low permeability but porosity is high. Shale has relatively low permeability and porosity. Volcanic rock and low-permeability sandstone have a wider range of permeability and porosity. The relationships of porosity and permeability of four different kinds of lithological reservoirs are shown in Fig. 1. It can be seen from the figure that the correlation between porosity and the logarithm of permeability of sedimentary tuff and shale is not obvious. In addition, there is a good correlation between porosity and the logarithm of permeability

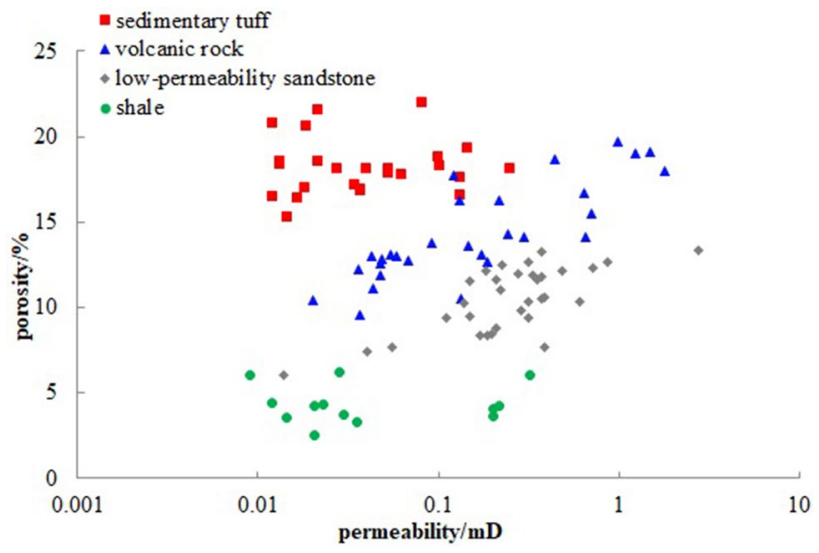

Fig. 1 Relationship between porosity and permeability of four different kinds of lithological reservoirs

of low-permeability sandstone and volcanic rock: with the increase of permeability, the porosity also increases continuously.

From the perspective of permeability alone, the order of the permeability of four different kinds of lithological reservoirs is as follows: low-permeability sandstone, volcanic rock, sedimentary tuff and shale. From the perspective of porosity alone, the order of the porosity of four different kinds of lithological reservoirs is as follows: sedimentary tuff, volcanic rock, low-permeability sandstone and shale. The porosity of sedimentary tuff is about $15-25 \%$, while that of shale is only about $5 \%$. The pore space sizes of the four different kinds of lithological reservoirs directly affect the seepage flow capacity of the reservoirs.

\section{Development characteristics of micropores in four different kinds of lithological reservoirs}

The adsorption and desorption isotherms are the basic data for the study of adsorption phenomena as well as the solid surface and pores. And they are also the basis for the calculation of pore structure characteristic parameters such as specific surface area and pore size distribution. In the process of adsorption and desorption experiments, the desorption curves often fail to coincide with the adsorption

Table 1 Porosity and permeability of four different kinds of lithological reservoirs

\begin{tabular}{|c|c|c|c|c|c|}
\hline Lithology & $\begin{array}{l}\text { Number of } \\
\text { cores }\end{array}$ & $\begin{array}{l}\text { Range of permeabil- } \\
\text { ity }(\mathrm{mD})\end{array}$ & $\begin{array}{l}\text { Average permeabil- } \\
\text { ity }(\mathrm{mD})\end{array}$ & Range of porosity (\%) & $\begin{array}{l}\text { Average } \\
\text { porosity } \\
(\%)\end{array}$ \\
\hline Volcanic rock & 33 & $0.020-5.529$ & 0.586 & $9.595-29.625$ & 15.019 \\
\hline Sedimentary tuff & 25 & $0.012-0.246$ & 0.057 & $15.320-22.011$ & 18.242 \\
\hline Shale & 17 & $0.009-2.862$ & 0.260 & $2.496-12.959$ & 5.431 \\
\hline Low-permeability sandstone & 32 & $0.014-2.738$ & 0.367 & $6.045-13.338$ & 10.489 \\
\hline
\end{tabular}




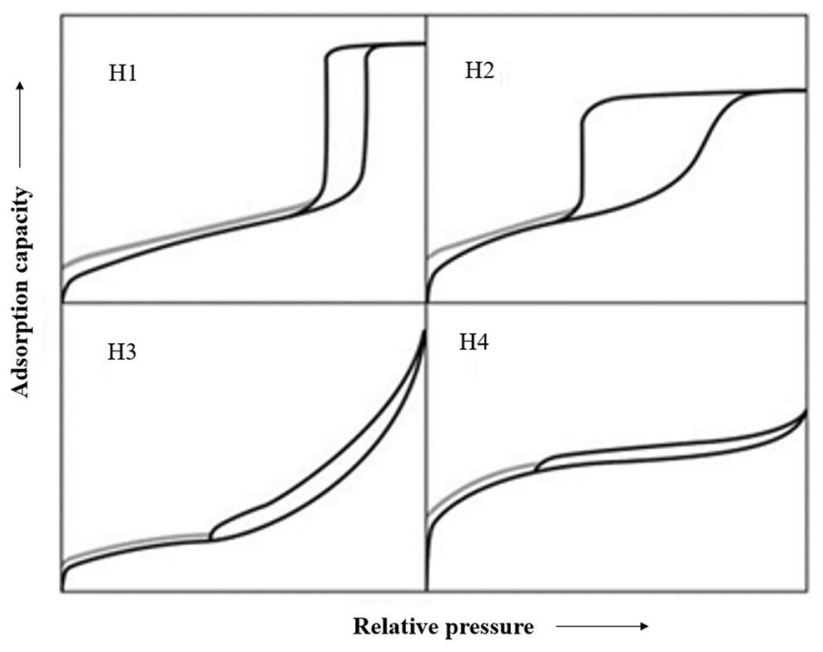

Fig. 2 Types of adsorption and desorption isotherms

curves (Fig. 2). The specific shape of adsorption and desorption isotherms is also an external reflection of the pore configuration.

The absorption and desorption isotherms of four different kinds of lithological reservoirs in the basin of western China are shown in Fig. 3. It indicates from the figure that the pore characteristics of different kinds of lithological reservoirs have part of consistency: the absorption and desorption isotherms of shale, low-permeability sandstone and volcanic rock are mainly $\mathrm{H} 2$ and $\mathrm{H} 3$ types. The pore configuration is mainly for the bottle shape holes, large piece cavity capillary holes and grooves, the matrix pores have weak seepage flow capacity. The absorption and desorption isotherms of sedimentary tuff are mainly $\mathrm{H} 3$ type, and the pore configuration is mainly capillary pores.

Parameters such as the specific surface of reservoir cores, pore volume, average pore radius, porosity and percentage of pores can be obtained from the low-temperature nitrogen adsorption and desorption technology results. Then, the nanoscale characteristics of rock samples can be quantitatively analyzed. When the pore volume and average pore radius are large but the specific surface area is small, the content of nano-pores in samples is small and the development degree of nano-pores is low. On the contrary, when the pore volume and average pore radius are small but the specific surface area is large, the content of nano-pores in samples is large and the development degree of nano-pores is high. 40 pieces of cores with four different kinds of lithological reservoirs in the basin of western China are summarized, and the results are shown in Table 2:

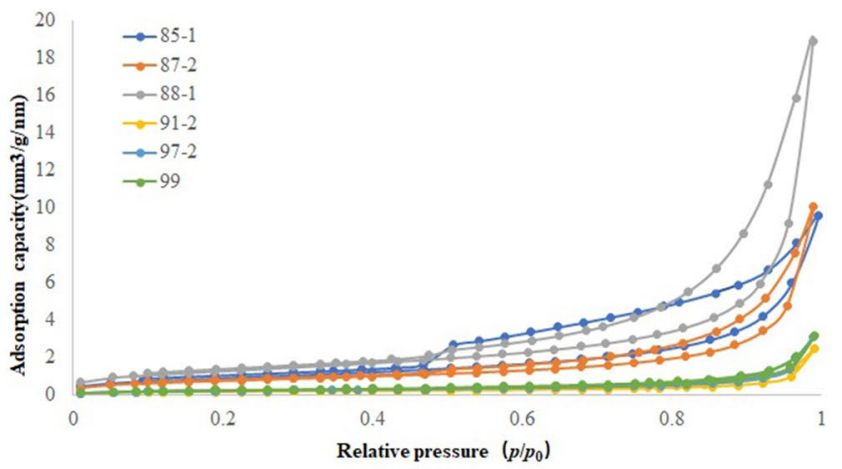

(A)

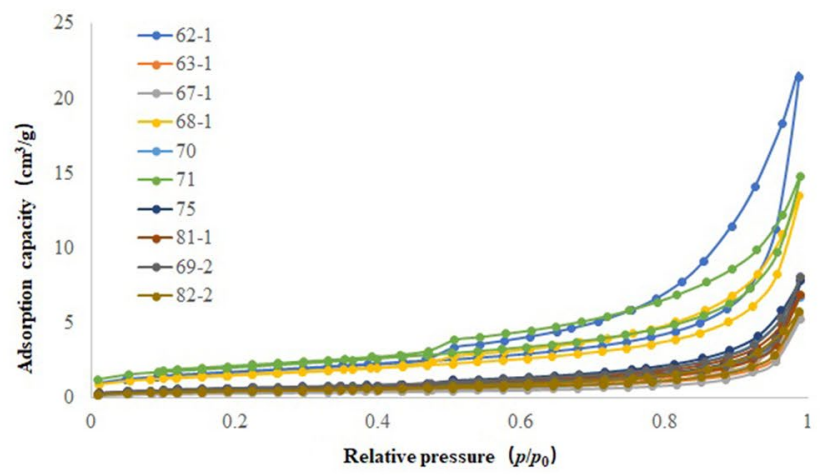

(C)

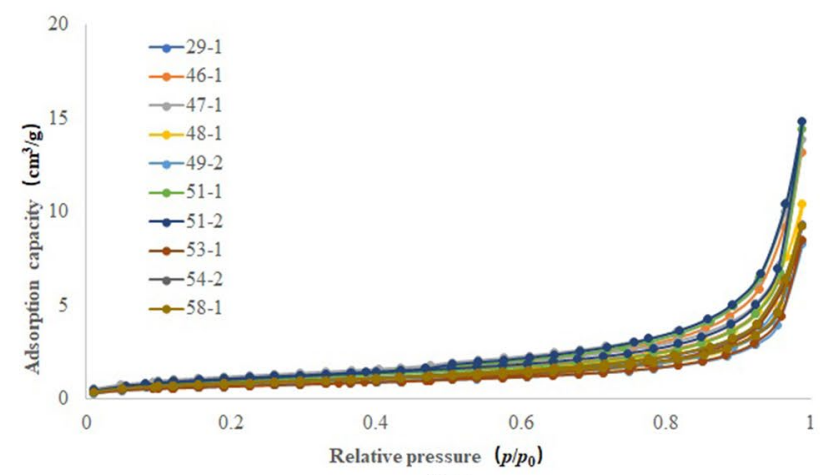

(B)

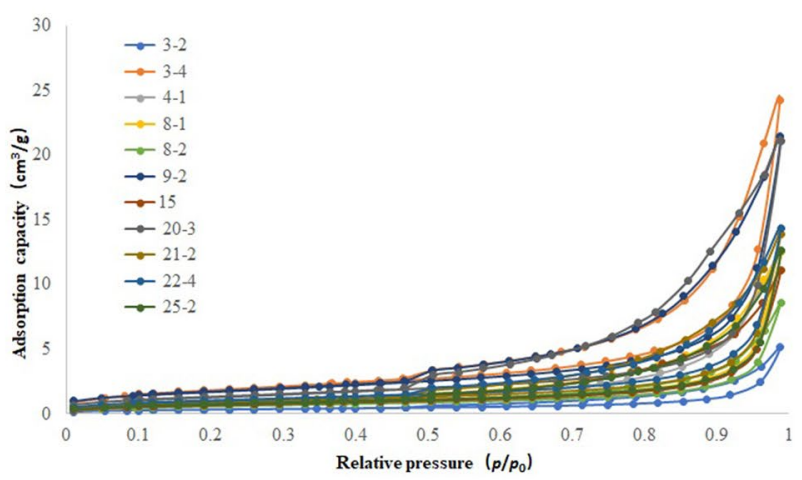

(D)

Fig. 3 Adsorption and desorption isotherms of four different kinds of lithological reservoirs 
Table 2 Experimental data of low-temperature adsorption and desorption experiment

\begin{tabular}{|c|c|c|c|c|c|c|}
\hline \multirow[t]{2}{*}{ Lithology } & \multirow[t]{2}{*}{$\begin{array}{l}\text { Average poros- } \\
\text { ity }(\%)\end{array}$} & \multirow[t]{2}{*}{$\begin{array}{l}\text { Average perme- } \\
\text { ability (mD) }\end{array}$} & \multicolumn{4}{|c|}{$\begin{array}{l}\text { Mean results of low-temperature adsorption and desorption technology } \\
\text { experiment }\end{array}$} \\
\hline & & & $\begin{array}{l}\text { Pore volume } \\
\left(\mathrm{mm}^{3} / \mathrm{g}\right)\end{array}$ & $\begin{array}{l}\text { Average pore } \\
\text { radius }(\mathrm{nm})\end{array}$ & $\begin{array}{l}\text { Specific surface } \\
\text { area }\left(\mathrm{m}^{2} / \mathrm{g}\right)\end{array}$ & $\begin{array}{l}\text { Micropore } \\
\text { percentage } \\
(\%)\end{array}$ \\
\hline Sedimentary tuff & 18.32 & 0.44 & 15.94 & 14.98 & 2.99 & 25.10 \\
\hline Low-permeability sandstone & 9.65 & 0.25 & 12.13 & 13.44 & 6.92 & 32.76 \\
\hline Shale & 5.92 & 0.08 & 11.83 & 13.27 & 6.21 & 33.52 \\
\hline Volcanic rocks & 14.26 & 0.19 & 24.51 & 11.65 & 4.41 & 40.01 \\
\hline
\end{tabular}

It can be seen from the table that among four different kinds of lithological reservoirs, low-permeability sandstone reservoir has the largest specific surface area, and it decreases in the order of low-permeability sandstone, shale, volcanic rock and sedimentary tuff. On the one hand, the large specific surface area is due to the large porosity inside the reservoirs. The large porosity inside the reservoirs leads to a large number of pores. On the other hand, if the porosity is the same, the more micropores (pore radius smaller than $50 \mathrm{~nm}$ ), the larger the specific surface area.

Pore volume refers to the volume of micropores per unit mass. It can be seen from the table that pore volume of volcanic rock is the largest, followed by those of sedimentary tuff, low-permeability sandstone and shale. Average pore radius refers to the average radius of micropores. The maximum average pore radius of sedimentary tuff reservoirs is $14.98 \mathrm{~nm}$. Micropore percentage refers to the percentage of micropores in the total pores of the core, and it varies greatly among the cores of the four different kinds of lithological reservoirs. The micropore percentage of low-permeability sandstone is the largest, accounting for $45.63 \%$; the percentage of micropores in shale is the smallest, accounting for $33.52 \%$.

Among the four different kinds of lithological reservoirs, volcanic rock reservoir has the largest micropore content, the development difficulty is large. The sedimentary tuff reservoir has less small micropore content, and average pore radius of sedimentary tuff reservoir is large, so the development difficulty is the least. The content of micropores in low-permeability sandstone and shale is between the above two, accounting for about $30 \%$.

\section{Pore structure characteristics of four different kinds of lithological reservoirs}

The capillary pressure method is to inject mercury into the pore system of the core and obtain the relationship between capillary pressure and mercury saturation by monitoring the fluctuation of capillary pressure and the change of in and out mercury contents. The corresponding pore radius can be calculated with a formula. High-pressure mercury injection experiment can be used to quantitatively measure the size of the pore throat, degree of sorting, connectivity and seepage flow capacity. In the process of mercury injection, mercury in the pores of the rock is the non-wetting phase and air is the wetting phase. The process of mercury injection is a process of non-wetting phase displacing the wetting phase. When the injection pressure is higher than the corresponding capillary pressure of the pores, mercury begins to fill the pores. When the injection pressure is equal to the capillary pressure, the corresponding capillary radius is the throat radius. The amount of mercury is the volume of pores inside. Continually changing the injection pressure, the capillary pressure curve and the pore throat distribution curve can be obtained. A large number of characteristic parameters of pore structures can be obtained from the capillary pressure curve of high-pressure mercury injection.

The pore characteristic parameters of 40 pieces of cores from four different kinds of lithological reservoirs are measured by high-pressure mercury injection. The results are shown in Table 3:

It can be seen from the table that volcanic rock has the largest average maximum throat radius among four different kinds of lithological reservoirs, followed by low-permeability sandstone, shale and sedimentary tuff. Showing that on the aspect of development degree of macropores, among the four kinds of lithological reservoirs, macropores are well developed in volcanic rock. Volcanic rock has the largest average throat radius, followed by sedimentary tuff, low-permeability sandstone and shale, indicating that more macropores are developed in volcanic rock, but few macropores are developed in the other kinds of lithological reservoirs. Low-permeability sandstone has the largest main throat radius, followed by volcanic rock, sedimentary tuff and shale, indicating that the seepage flow capacity of lowpermeability sandstone reservoir and volcanic rock reservoir are far better than that of sedimentary tuff reservoir and shale reservoir. The main throat radius values of all cores with permeability smaller than $1 \mathrm{mD}$ were counted with the results shown in Fig. 4. 
Table 3 Experimental results of high-pressure mercury injection

\begin{tabular}{|c|c|c|c|c|c|c|c|c|c|}
\hline Lithology & $\begin{array}{l}\text { Average } \\
\text { poros- } \\
\text { ity } / \%\end{array}$ & $\begin{array}{l}\text { Average } \\
\text { permeabil- } \\
\text { ity/mD }\end{array}$ & $\begin{array}{l}\text { Average } \\
\text { maximum } \\
\text { throat radius/ } \\
\mu \mathrm{m}\end{array}$ & $\begin{array}{l}\text { Average } \\
\text { throat } \\
\text { radius } / \mu \mathrm{m}\end{array}$ & $\begin{array}{l}\text { Average } \\
\text { main throat } \\
\text { radius } / \mu \mathrm{m}\end{array}$ & $\begin{array}{l}\text { Average } \\
\text { maximum } \\
\text { mercury } \\
\text { saturation/\% }\end{array}$ & $\begin{array}{l}\text { Average } \\
\text { relative } \\
\text { sorting coef- } \\
\text { ficient }\end{array}$ & $\begin{array}{l}\text { Average } \\
\text { uniformity } \\
\text { coefficient }\end{array}$ & $\begin{array}{l}\text { Average } \\
\text { displacement } \\
\text { pressure/MPa }\end{array}$ \\
\hline $\begin{array}{l}\text { Volcanic } \\
\text { rock }\end{array}$ & 14.35 & 0.63 & 4.35 & 0.79 & 0.75 & 59.17 & 4.14 & 0.18 & 0.43 \\
\hline $\begin{array}{l}\text { Sedimentary } \\
\text { tuff }\end{array}$ & 18.32 & 0.04 & 0.73 & 0.26 & 0.33 & 77.32 & 3.43 & 0.14 & 1.36 \\
\hline $\begin{array}{l}\text { Low-per- } \\
\text { meability } \\
\text { sandstone }\end{array}$ & 9.65 & 0.25 & 1.75 & 0.15 & 0.76 & 69.83 & 4.76 & 0.08 & 0.56 \\
\hline Shale & 5.87 & 0.09 & 0.90 & 0.07 & 0.17 & 77.99 & 3.39 & 0.15 & 4.46 \\
\hline
\end{tabular}

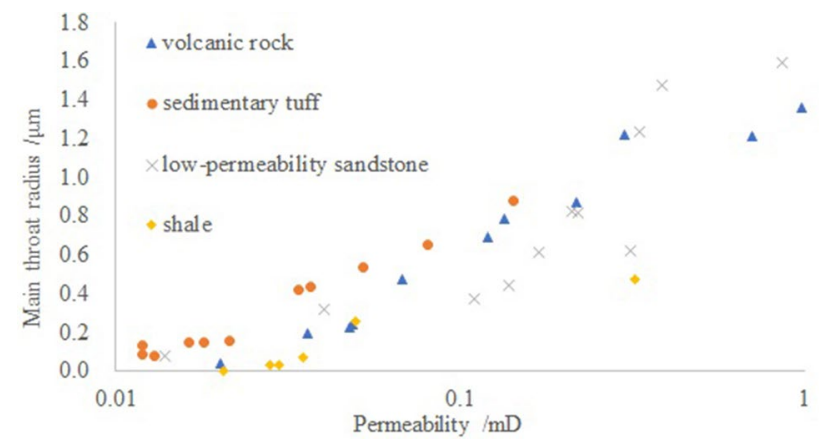

Fig. 4 Relationship between main throat radius and permeability of different kinds of lithological reservoirs

It can be seen from Fig. 4 that there is a positive correlation between the main throat radius and permeability of the core samples with four kinds of lithological reservoirs, and the main throat radius is increased with the increment of permeability. In addition, under the same permeability, there is still a big difference in the main throat radius of the four kinds of lithological reservoirs: the main throat radius of sedimentary tuff is the largest and that of shale is the smallest, while the main throat radius of volcanic rock and low-permeability sandstone is between the above two. Furthermore, there are big jumps in the main throat radius of low-permeability sandstone, which indicates that the homogeneity of sandstone is poor.

It can also be seen that although volcanic rock and lowpermeability sandstone have stronger seepage flow capacity and better pore-development on the whole, but under the same low-permeability condition, sedimentary tuff has better seepage capacity, followed by volcanic rock, low-permeability sandstone. Shale still has the weakest seepage capacity.

For the tight cores with a permeability of less than $1 \mathrm{mD}$, its microscopic pores are mainly distributed at the nanometer, submicron and micron levels. The micropore structures of 40 pieces of tight core are tested and analyzed by using above two methods. Through the high-pressure mercury injection test, the pore volume controlled by the pore throats above nanoscale can be determined by the amount of mercury injected under different pressures. Combined with lowtemperature nitrogen adsorption and desorption technology, the proportion of nanoscale pores can be measured and calculated, and the size of pore space controlled by throats at different levels can be analyzed.

The corresponding relationship between the contribution rates of permeability and throat radius can be calculated by Formula (Hong et al. (2014); Zhengming et al. 2007):

$\Delta K_{i}=\frac{r_{i}^{2} \alpha_{i}}{\sum r_{i}^{2} \alpha_{i}}$

where $r_{i}$ is the radius of a certain throat of the core, $\mathrm{m} ; \alpha_{i}$ is the normalized distribution frequency of a certain throat radius, $\%$. The test results are as shown in Table 4 :

Based on Table 4, it can be concluded that the characteristics of pore throat distribution with four different kinds of lithological reservoirs are quite different (Fig. 5):

(1) In terms of throat distribution, both nanoscale pore throats and submicron scale pore throats are the main storage spaces of four kinds of lithological reservoirs. Each type of lithological reservoir contains a small amount of micron scale pore throats, but the proportion is relatively small. Shale has the maximum proportion of nanoscale pore throats, accounting for about $60 \%$ of the total pore throats, followed by volcanic rock, lowpermeability sandstone. And the content of nanoscale pore throats in sedimentary tuff is the smallest.

The proportion of submicron scale pore throats in sedimentary tuff is the largest, reaching more than $45 \%$, followed by low-permeability sandstone, volcanic rock and shale. The proportion of micron scale pore throats of low-permeability sandstone, shale and volcanic rock 
Table 4 Pore throat distribution and permeability contribution distribution of different kinds of lithological reservoirs

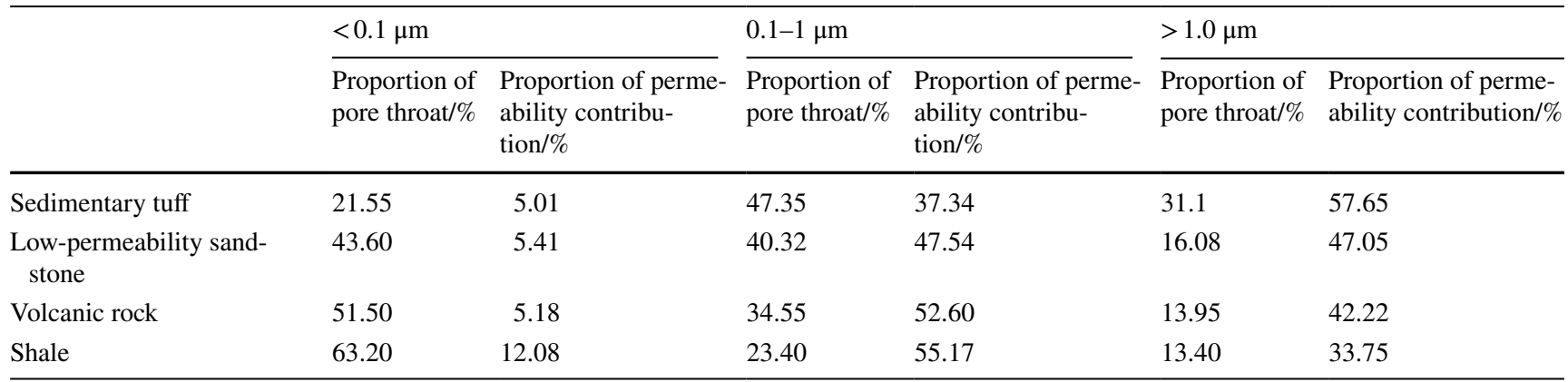

Fig. 5 Pore throat distribution and permeability contribution distribution in different kinds of lithological reservoirs

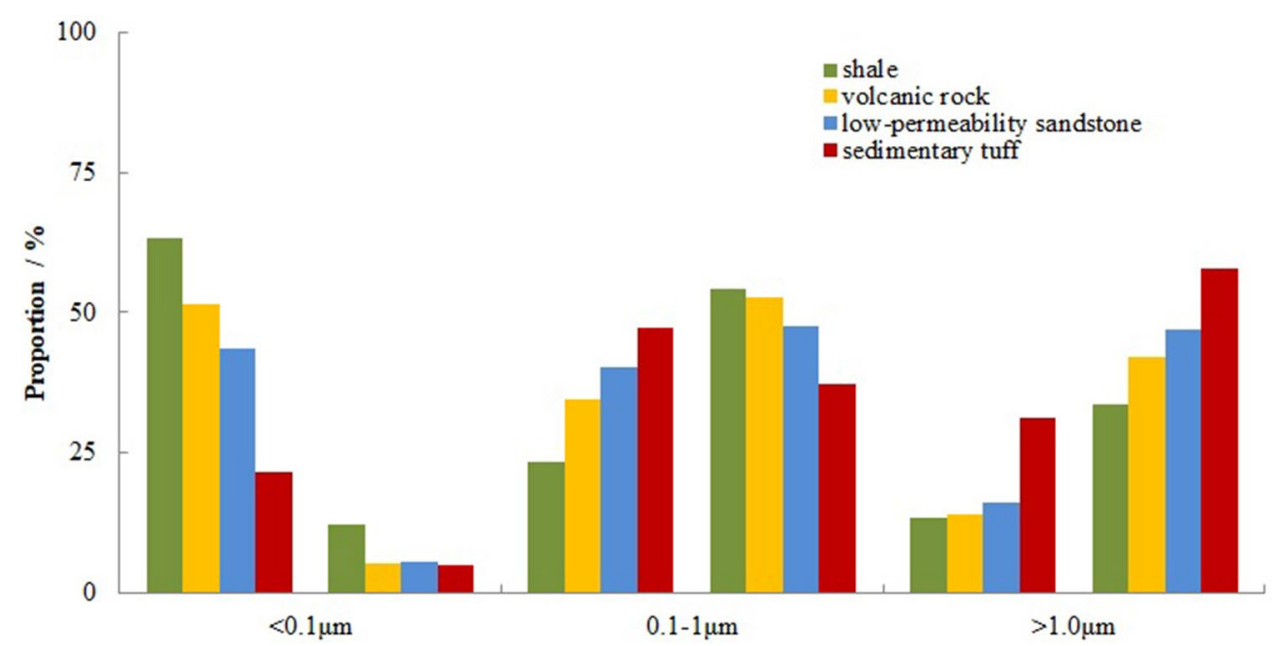

are relatively small, accounting for about $15 \%$. While the proportion of micron scale pore throats of sedimentary tuff is relatively large, which is about twice that of other types of lithological reservoirs, accounting for about $30 \%$.

(2) In terms of the contribution distribution of permeability, both submicron scale pore throats and micron scale pore throats are the main reservoir spaces of the reservoirs with four kinds of lithological reservoirs. Nanoscale pore throats of all four kinds of lithological reservoirs have a certain contribution to permeability, but the contribution rates are low. The permeability contributed by the nanoscale pores of shale is the highest, exceeding 10\%, among the four types of lithological reservoirs. While the contribution of the nanoscale pores of other three types of lithological reservoirs is around $5 \%$. The main permeability contribution of shale, volcanic rock, and low-permeability sandstone comes from submicron pore throats. The permeability provided by submicron pore throats of shale is greater than that of volcanic rock and low-permeability sandstone. However, the permeability contribution provided by micron pore throats in shale is significantly smaller

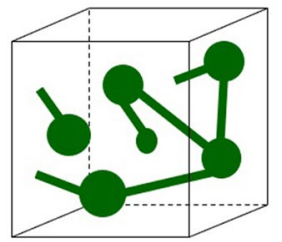

(A) sedimentary tuff

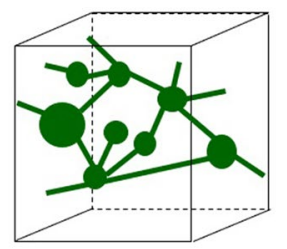

(C) low-permeability sandstone

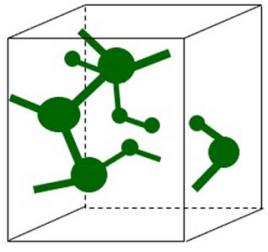

(B) volcanic rock

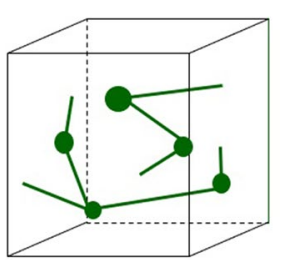

(D) shale
Fig. 6 Ball-and-stick model of micropore structure of different reservoirs

than that in volcanic rock and low-permeability sandstone. The permeability contribution of sedimentary 
tuff is mainly provided by micron scale pore throats, which accounts for more than $55 \%$.

\section{Ball-and-stick model of pore structure of cores with complex lithology}

It can be concluded from the above that the pore structure and permeability contribution of the reservoirs with four different kinds of lithological reservoirs vary greatly. Based on the results of low-temperature nitrogen adsorption and desorption technology and high-pressure mercury injection experiment, the microscopic pore structure of the cores of different kinds of lithological reservoirs can be preliminarily understood (Fig. 6):

(1) Sedimentary tuff reservoir: the total porosity and pore space volume of sedimentary tuff reservoir are relatively large. The micropore content is small, and the average pore radius is large. However, the maximum pore radius is small, and the whole pores belong to the middle pores. Under the same permeability, the radius of the main throat is significantly larger than that of other types of reservoirs, indicating that the throat development level is relatively high.

(2) Low-permeability sandstone reservoir: the total porosity of low-permeability sandstone reservoirs is slightly smaller than that of sedimentary tuff reservoir, and the pore space volume is relatively small. The micropore content is more than that of sedimentary tuff reservoir, and the average pore radius is smaller than that of sedimentary tuff reservoir. However, the maximum pore radius and the main throat radius of low-permeability sandstone reservoir are large, indicating that the micropores of low-permeability sandstone are not well developed and their homogeneity is poor.

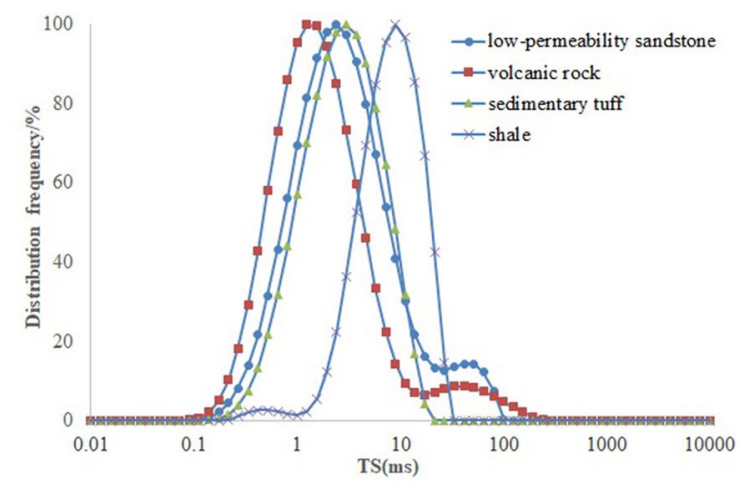

(A)
(3) Volcanic rock reservoir: the total porosity of volcanic rock reservoir is also relatively large, which is similar to the porosity level of sedimentary tuff reservoir, and their pore space volume is relatively large. Volcanic rock reservoir has the most micropore content, so the average pore radius is relatively small. However, the maximum pore radius of volcanic rock reservoir is very large, and the main throat radius is also large, which indicates that microscopic pores of volcanic rock reservoir are not well developed and the homogeneity property is poor.

(4) Shale reservoir: the total porosity of shale reservoir is very small, and their pore space volume is also relatively small. The micropore content of hale reservoir is similar to that of low-permeability sandstone. The average pore radius, maximum pore radius and main throat radius are all relatively small, indicating that micropores are poorly developed in shale reservoir.

\section{Characteristics of occurrence of fluids in four different kinds of lithological reservoirs}

Low-permeability reservoirs tend to be saturated with oil, gas and water. The pore structure, clay content and distribution of reservoirs are more complex. The interaction between solid-liquid interface and liquid-liquid interface has a greater impact on the seepage flow of fluids. Reservoirs have poor physical properties, small pore throats, high proportion of nanoscale pore throat development, and complex oil phase occurrence. Understanding the occurrence state and contribution of oil phase in pores of different sizes is of great significance for fine evaluation and effective development of reservoirs.

Movable fluids are tested using the nuclear magnetic resonance and centrifugal technique. Quantitative measurement

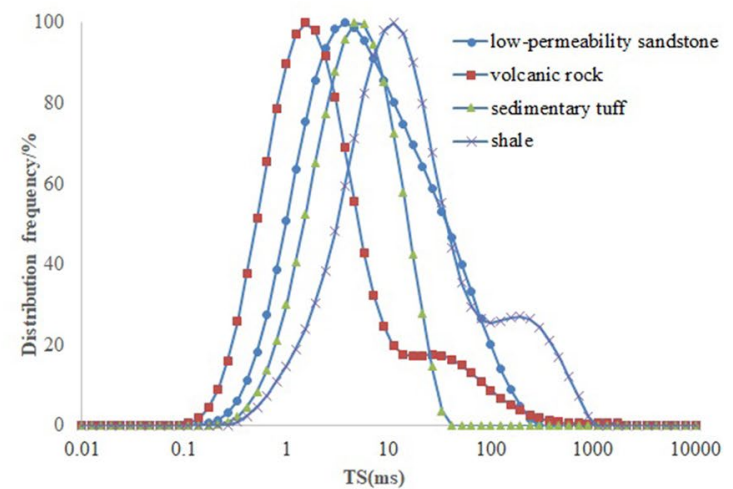

(B)

Fig. 7 NMR graph of different kinds of reservoirs under the same permeability 
of hydrogen nucleus contained in fluids in the pores of cores, using nuclear magnetic resonance (NMR) can reflect the pore size distribution and fluid volume in the pores of different sizes (Xuewu et al. 2013). Nuclear magnetic resonance (NMR) experiments were performed by core NMR analyzer recore-04, Institute of percolation, Chinese Academy of Sciences, and gas-water high-speed centrifugation experiments were performed by core centrifuge pc-18. The NMR-centrifugal graph of the four different kinds of lithological reservoirs is as shown in Fig. 7. It indicates from the figure that under the same permeability condition, volcanic rock has the largest range of NMR graph and that of sedimentary tuff has the smallest. The ranges of NMR graph of low-permeability sandstone and shale are between them. The NMR graph of four different kinds of lithological reservoirs do not have obvious bimodal characteristics. With the increase of permeability, the right peak ratio gradually begins to increase, the amount of movable fluid to increase and the development potential to get better.

Meanwhile, by calculating the fluid distribution curves obtained through before and after centrifugation with saturated water, the movable fluids distribution in different sizes of throats can be obtained. According to the $T_{2}$ spectrum of the core after removal of movable water, the accumulated $\mathrm{T}_{2}$ signal quantity is calculated, and then a point is found on the $\mathrm{T}_{2}$ spectrum of the fully saturated water core, so that the accumulated $\mathrm{T}_{2}$ signal quantity on the left side is equal to the total accumulated $\mathrm{T}_{2}$ signal quantity after removal of movable water, and the $T_{2}$ value corresponding to this point is the $\mathrm{T}_{2}$ cutoff value. According to the experimental results and the arithmetic average, the $\mathrm{T}_{2}$ cutoff value of volcanic rock, sedimentary tuff, low-permeability sandstone and shale is $4.629,16.804,5.308$ and 6.324 , respectively.
According to the $\mathrm{T}_{2}$ cutoff value selected above, the movable fluid content of each reservoir core calculated is shown in Fig. 8. It can be seen from Fig. 8 that there is a positive correlation between the saturation of movable fluid and permeability of the four different kinds of lithological reservoirs. With the continuous increase of permeability, the saturation of the movable fluid increases from $15 \%$ to about $65 \%$. When the permeability is less than $0.5 \mathrm{mD}$, the saturation of the movable fluids is, from big to small, sedimentary tuff, volcanic rock, low-permeability sandstone and shale. When the permeability is greater than $0.5 \mathrm{mD}$, the saturation of the movable fluids is, from big to small, sedimentary tuff, low-permeability sandstone, volcanic rock and shale.

On the basis of saturated water, the cores were centrifuged at 20psi, 42 psi, 209 psi and 417 psi, respectively, and the NMR response signals under different centrifugal forces were recorded. The movable fluid content controlled by different sizes of pore throats can be obtained by conversion, which provides a basis for the study of the distribution of movable fluid in the core. The movable fluids content controlled by different pore spaces is shown in Fig. 9.

It is observed from the figure that sedimentary tuff has the highest total movable fluid content, for about $50 \%$, followed by low-permeability sandstone and volcanic rock. When the permeability is small, the movable fluid content is about $30 \%$. With the increase of permeability, the movable fluid content can reach about $50 \%$. Shale has the lowest movable fluid content. With the increase of permeability, movable fluid content of shale reservoir also increases gradually, but the amplitude of the increment is small, and the total movable fluid content of shale reservoir is low.

The movable fluid content controlled by nanoscale pores of sedimentary tuff and volcanic rock is clearly smaller than
Fig. 8 Relationship between permeability and the saturation of movable fluid

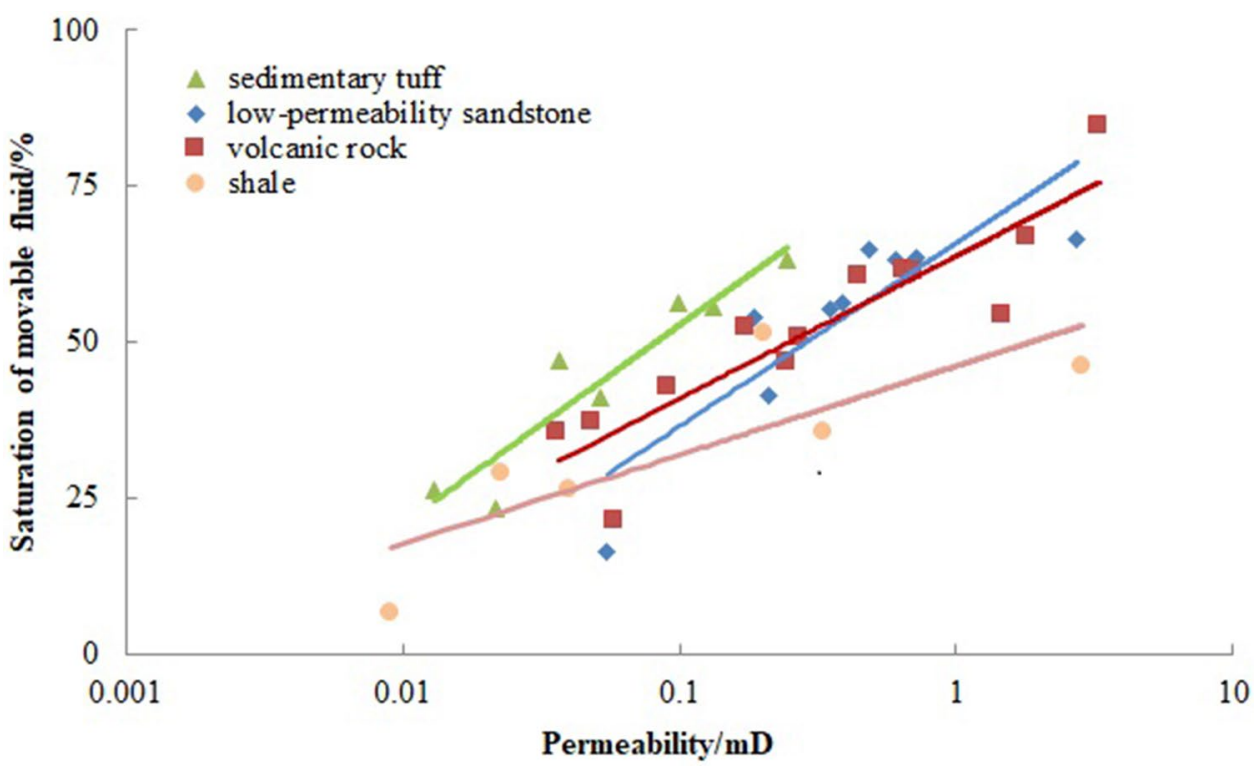




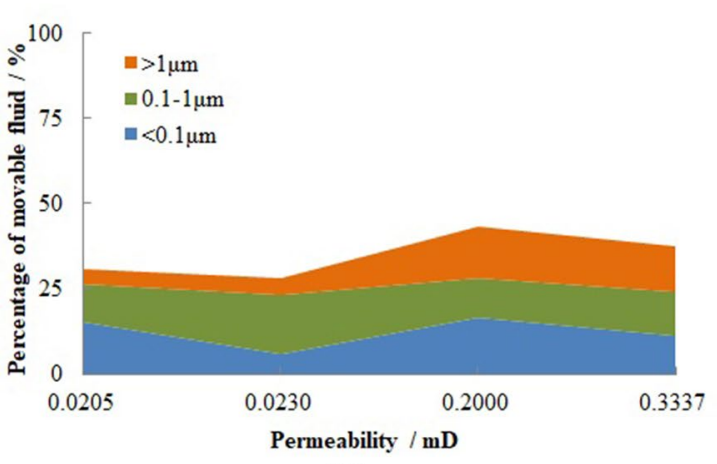

(A)

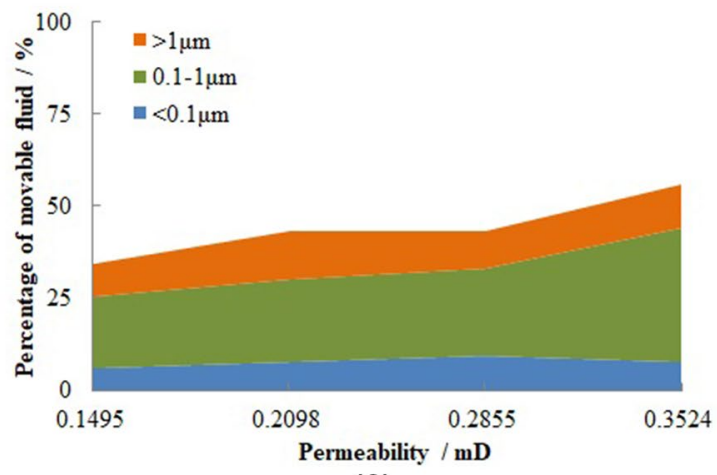

(C)

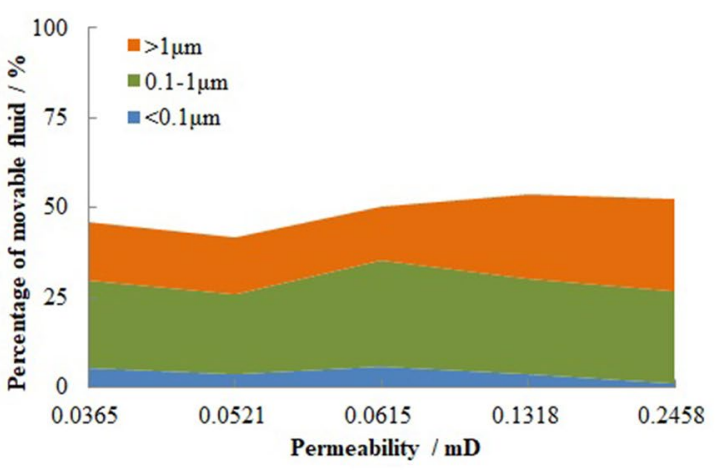

(B)

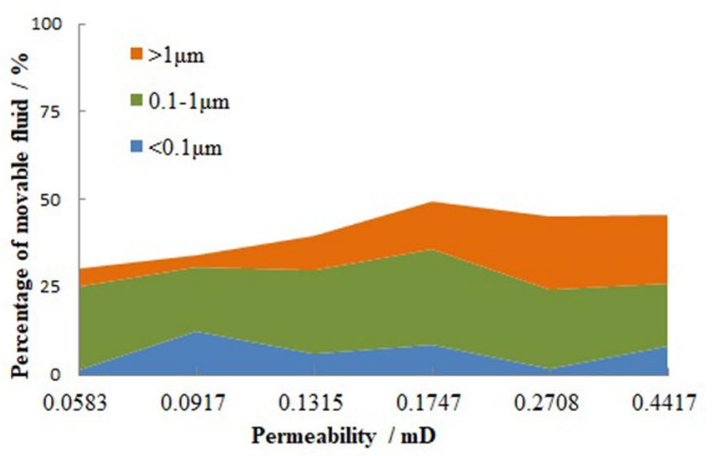

(D)

Fig. 9 Relative percentage of movable fluids controlled by throats of different sizes

Table 5 Relative saturation of the movable fluids controlled by different sizes of throats i

\begin{tabular}{llll}
\hline Lithology & \multicolumn{2}{l}{$\begin{array}{l}\text { Relative saturation of the movable fluids controlled by different sizes } \\
\text { of throats } / \%\end{array}$} \\
\cline { 2 - 4 } & $\begin{array}{l}\text { Nanoscale throats } \\
r \leq 0.1 \mu \mathrm{m}\end{array}$ & $\begin{array}{l}\text { Submicron scale throats } \\
0.1<r \leq 1 \mu \mathrm{m}\end{array}$ & $\begin{array}{l}\text { Micron scale } \\
\text { throats } r>1 \mu \mathrm{m}\end{array}$ \\
\hline Sedimentary tuff & 8.00 & 52.38 & 39.63 \\
Volcanic rock & 12.52 & 50.62 & 36.86 \\
Low-permeability sandstone & 17.13 & 58.22 & 24.64 \\
Shale & 32.78 & 49.14 & 18.08 \\
\hline
\end{tabular}

that of low-permeability sandstone and shale. Compared with other kinds of lithological reservoirs, the value of the movable fluid controlled by nanoscale pores of shale reservoir is the highest. The movable fluid content controlled by submicron scale pores of the four kinds of lithological reservoirs is the highest, followed by micron scale pores. The relative movable fluid saturation controlled by different sizes of pores in the four kinds of lithological reservoirs is shown in Table 5:

It is clear from the table that the movable fluids of the four kinds of lithological reservoirs are mainly controlled by submicron scale and micron scale throats, while only a small amount of movable fluids are controlled by nanoscale throats. The movable fluids in shale reservoir occur in submicron scale and nanoscale pores, and the movable fluids of sedimentary tuff reservoir and volcanic rock reservoir mainly occur in micron scale and submicron scale pores. The movable fluids of low-permeability sandstone reservoir mainly occur in submicron scale pores.

There is also a good corresponding relationship between the percentage of movable fluids controlled by different sizes of four kinds of lithological reservoirs, the abovementioned throat distribution is shown in Fig. 10. The content of nanoscale pores in sedimentary tuff reservoir is low, and 
Fig. 10 The movable fluids content controlled by different sizes of throats

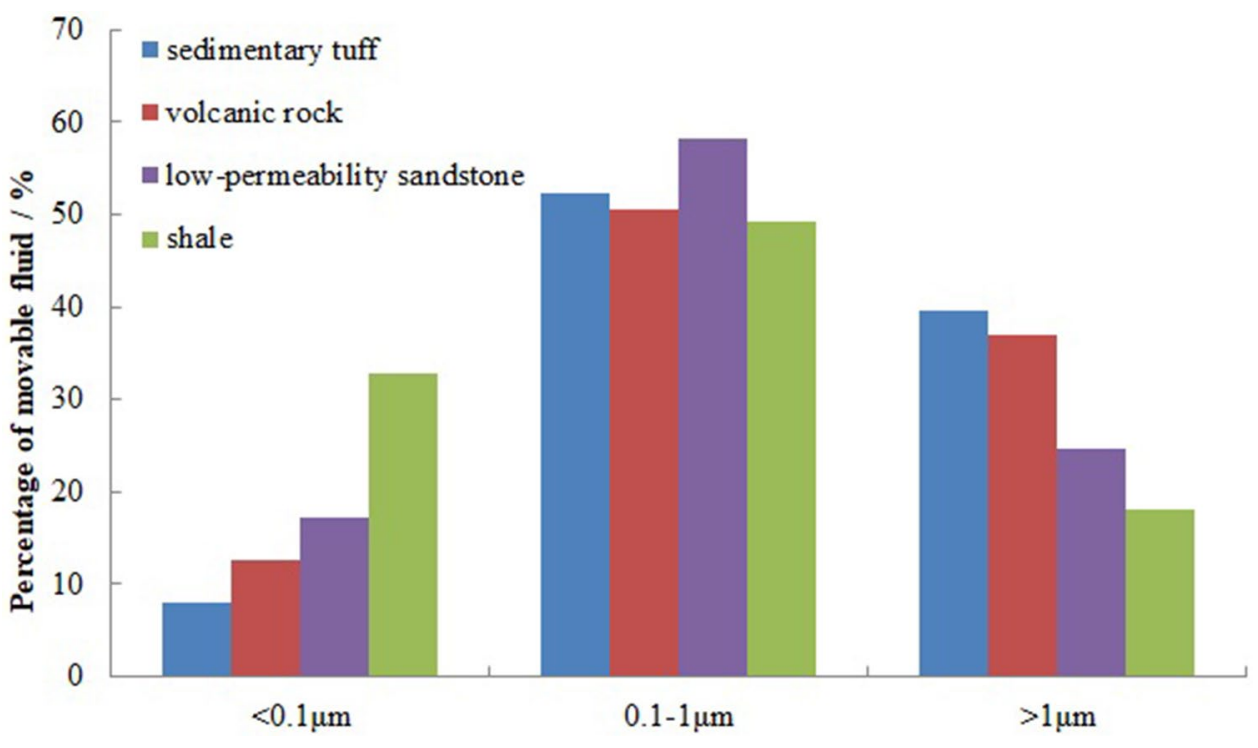

they control the least movable fluids, for only $8 \%$. The content of the micro-nanoscale throats is the highest, and they control the most movable fluids. The content of micron pores of shale reservoir is the least, and the corresponding movable fluids controlled by micron throats are also the least.

Shale reservoir has the most pore volume at nanoscale pores. But for shale reservoir, it is difficult for fluids in the nanoscale pores to be migrated, so submicron throats control the most movable fluids.

Fig. 11 Schematic diagram of the nonlinear seepage flow curve of a typical low-permeability reservoir

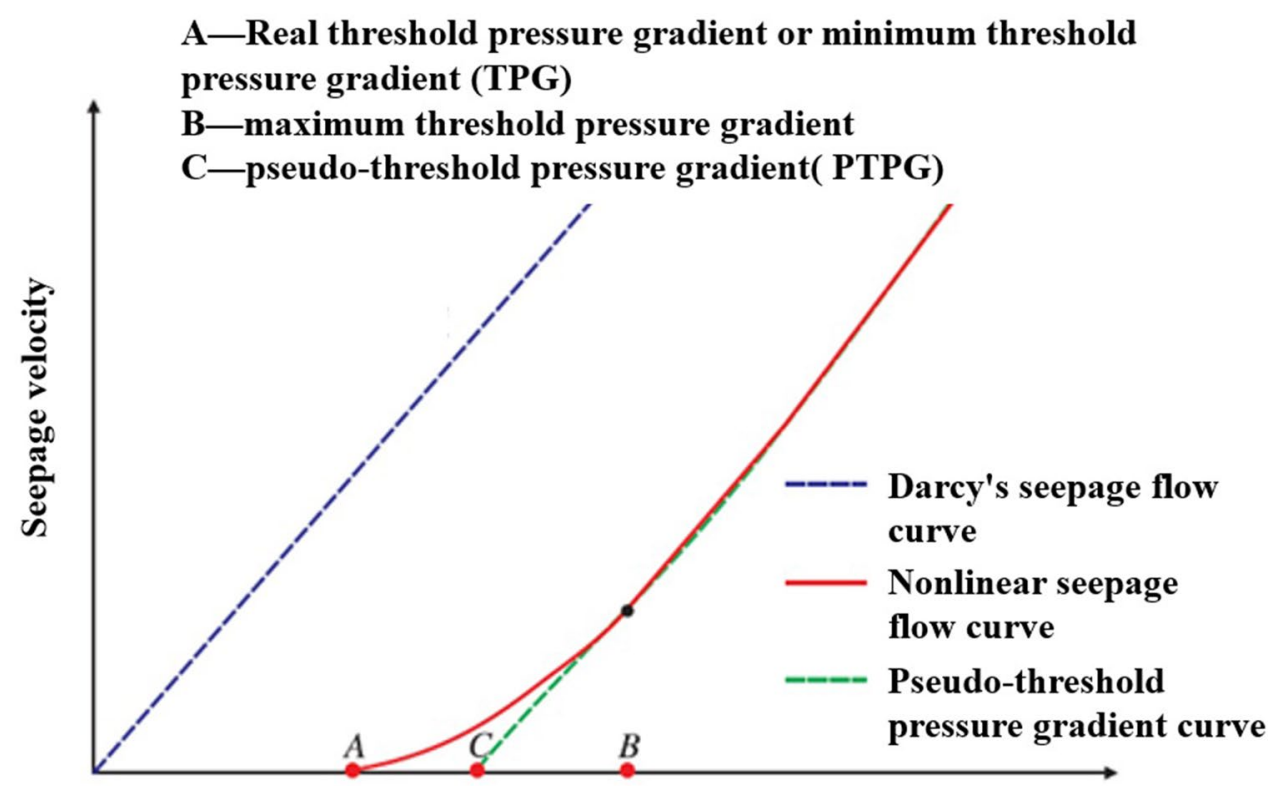

Displacement pressure gradient

Compared with the conventional low-permeability reservoirs, the pore structure of tight reservoirs is more complex, the pores are more subtle, and the connectivity between pores is poorer. Low permeability and greater seepage resistance make it more difficult to drive out the oil in the pores. Domestic and overseas scholars have proved through a large number of laboratory core experiments that the threshold pressure gradient is common in the process of tight reservoir development, which is characterized by low velocity nonlinear seepage flows. Hao et al. (2008) believe that the threshold pressure of oil-water phase seepage flow is

\section{Nonlinear seepage flow characteristics of four different kinds of lithological reservoirs}


Table 6 Results of the nonlinear seepage flow tests

\begin{tabular}{|c|c|c|c|c|c|c|}
\hline Lithology & Number & Length/cm & Diameter/cm & $\begin{array}{l}\text { Permeability/ } \\
\mathrm{mD}\end{array}$ & Porosity/\% & $\begin{array}{l}\text { Threshold pressure } \\
\text { gradient } / \mathrm{MPa} / \mathrm{m}\end{array}$ \\
\hline \multirow[t]{8}{*}{ Volcanic rock } & 1 & 4.61 & 2.47 & 0.13 & 16.29 & 0.47 \\
\hline & 2 & 4.16 & 2.48 & 0.17 & 13.06 & 0.41 \\
\hline & 3 & 4.35 & 2.47 & 0.27 & 17.39 & 0.30 \\
\hline & 4 & 3.94 & 2.47 & 0.44 & 18.72 & 0.28 \\
\hline & 5 & 2.59 & 2.47 & 0.65 & 16.69 & 0.24 \\
\hline & 6 & 4.42 & 2.47 & 0.71 & 15.50 & 0.23 \\
\hline & 7 & 4.46 & 2.48 & 1.48 & 19.10 & 0.22 \\
\hline & 8 & 4.47 & 2.48 & 1.79 & 18.02 & 0.20 \\
\hline \multirow[t]{4}{*}{ Sedimentary tuff } & 9 & 4.31 & 2.47 & 0.04 & 16.85 & 0.30 \\
\hline & 10 & 4.40 & 2.47 & 0.05 & 17.92 & 0.26 \\
\hline & 11 & 4.38 & 2.47 & 0.06 & 17.86 & 0.24 \\
\hline & 12 & 4.29 & 2.48 & 0.25 & 18.12 & 0.18 \\
\hline \multirow[t]{3}{*}{ Shale } & 13 & 4.41 & 2.47 & 0.02 & 4.32 & 0.94 \\
\hline & 14 & 4.82 & 2.48 & 0.33 & 7.25 & 0.53 \\
\hline & 15 & 4.41 & 2.46 & 2.86 & 3.82 & 0.32 \\
\hline \multirow[t]{5}{*}{ Low permeability sandstone } & 16 & 4.14 & 2.47 & 0.15 & 9.52 & 0.32 \\
\hline & 17 & 4.39 & 2.47 & 0.21 & 11.66 & 0.24 \\
\hline & 18 & 6.69 & 2.47 & 0.35 & 11.62 & 0.19 \\
\hline & 19 & 6.65 & 2.48 & 0.72 & 12.35 & 0.16 \\
\hline & 20 & 6.18 & 2.48 & 2.74 & 13.34 & 0.16 \\
\hline
\end{tabular}

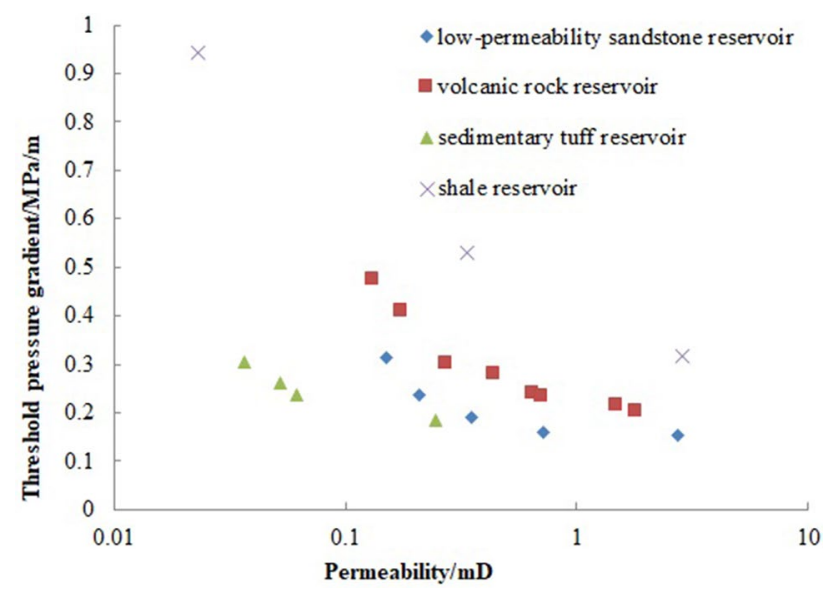

Fig. 12 Relationship between the permeability and threshold pressure gradient

greater than that of single-phase oil due to the capillary pressure and Jamin effect; Xuefen 2015 and Xing et al. (2013) obtained the seepage flow curves of single-phase water and oil through steady-state flow test and $\mathrm{CO}_{2}$ miscible flooding, respectively, and found that both of them had concave nonlinear segments, which verified the existence of nonlinear seepage flows. In addition, some scholars have proposed physical models of nonlinear seepage flows, such as the general model of nonlinear seepage flow (Yan-zhang et al. 2013), the nonlinear seepage flow model that takes into account the yield stress (Ruizhong et al. 2012), and the new viscosity modified seepage flow model that takes into account the microscopic action between liquid and solid (Hao-chuan et al. 2013).

It indicates from the typical nonlinear seepage curves of low-permeability reservoirs (Fig. 11) that the relationship between fluid seepage velocity and displacement pressure gradient no longer follows the conventional Darcy's Law, and they have the characteristics of nonlinear seepage flows in the initial stage and linear seepage flows in the later stage (Ying and Ciqun 2001; Shi et al. 2000). When the displacement pressure gradient is less than A, there is no flow in the system; When the displacement pressure gradient reaches A, the fluid begins to flow. When the displacement pressure gradient is larger than A but smaller than B, the fluid presents a nonlinear flow. When the displacement pressure gradient is larger than B, the fluid shows a Darcy flow. Extending the straight-line segment in the case of a linear seepage flow to intersect with the horizontal axis at Point $\mathrm{C}$, the pseudo-threshold pressure gradient can be obtained.

In this paper, the nonlinear seepage flow test system of the Seepage Institute of the Chinese Academy of Sciences is used to test the stable pressure-steady flow under different displacement pressures for the complex cores with four different kinds of lithological reservoirs. 


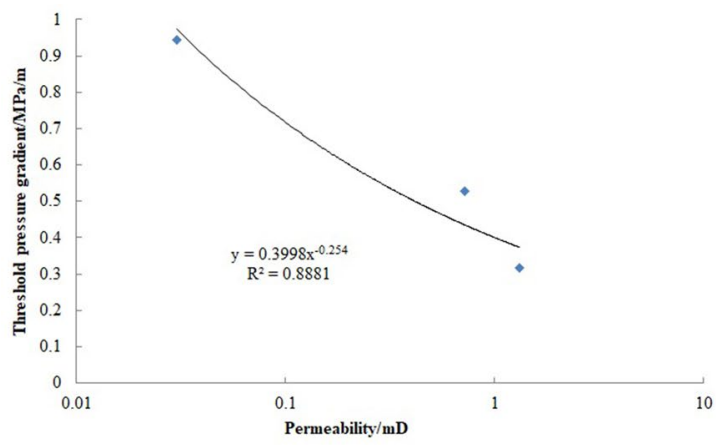

(A)

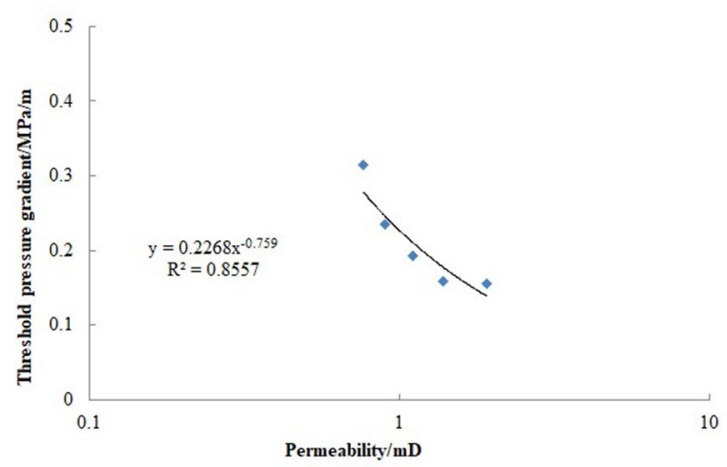

(C)

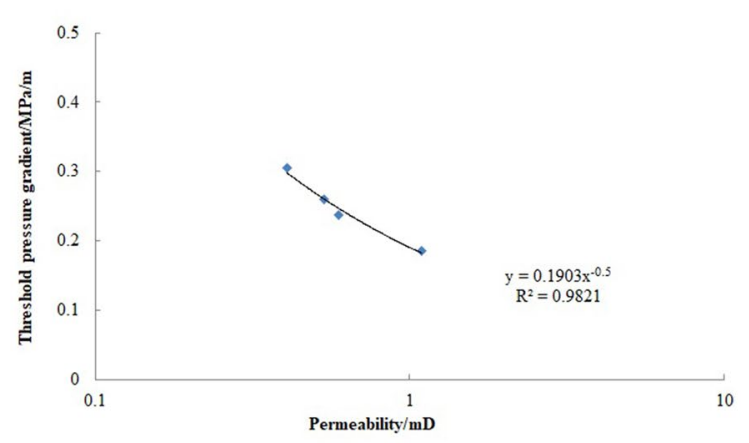

(B)

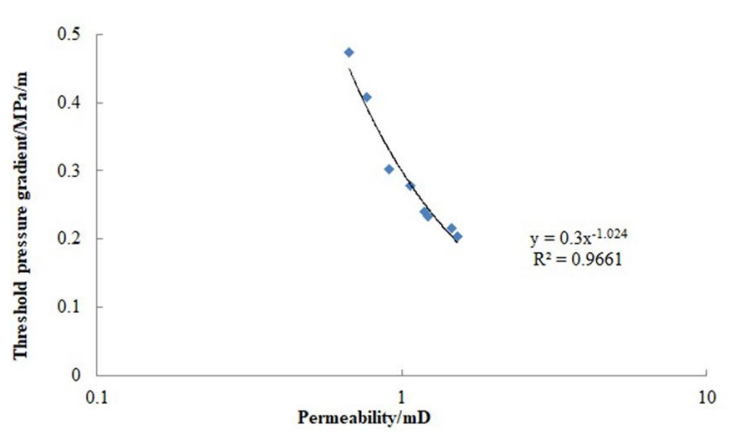

(D)

Fig. 13 The power law function of relationship between threshold pressure gradient and the permeability

Table 7 Results of the nonlinear seepage flow tests

\begin{tabular}{lllllll}
\hline Reservoir & Porosity/\% & $\begin{array}{l}\text { Gas permeabil- } \\
\text { ity/mD }\end{array}$ & $\begin{array}{l}\text { Water perme- } \\
\text { ability/mD }\end{array}$ & Magnification & $\begin{array}{l}\text { Threshold pressure } \\
\text { gradient/MPa/m }\end{array}$ & $\begin{array}{l}\text { Pore throat } \\
\text { radius/ } \mu \mathrm{m}\end{array}$ \\
\hline Sedimentary tuff & 18.12 & 0.25 & 0.15 & 1.64 & 0.18 & 1.09 \\
Low-permeability sandstone & 11.66 & 0.21 & 0.05 & 4.20 & 0.24 & 0.90 \\
Volcanic rock & 17.39 & 0.27 & 0.03 & 9.03 & 0.30 & 0.91 \\
Shale & 7.26 & 0.33 & 0.03 & 10.81 & 0.53 & 0.72 \\
\hline
\end{tabular}

Threshold pressure gradient parameters are obtained by monitoring the pressure changes of reservoir core during gas drive. Select the initial pressure of about $0.05 \sim 0.1 \mathrm{MPa}$, and make it rise to more than $10 \mathrm{MPa}$, each time the pressure increases to about twice the value of the previous stage pressure. In this process, the outlet flow rate is continuously detected and recorded after stabilization to obtain the starting pressure gradient law. The threshold pressure gradient values of each core are shown in Table 6.

Figure 12 shows the relationship between the threshold pressure gradient and permeability of each core. It is observed from the figure that there is a good power function relationship between the threshold pressure gradient and the logarithm of the permeability. With the increase of the permeability, the threshold pressure gradient decrease.
Under the same permeability, the threshold pressure gradients of the four different kinds of lithological reservoirs are decreased in the order of shale, volcanic rock, low-permeability sandstone and sedimentary tuff. This indicates that among the four different kinds of lithological reservoirs, sedimentary tuff reservoir is the least difficult to develop, shale reservoir is the most difficult, and volcanic rock reservoir and low-permeability sandstone reservoir are between them.

In addition, the results of this nonlinear seepage flow test have a good correlation with the microscopic pore results of the four different kinds of lithological reservoirs obtained as mentioned above. The pores of shale are the smallest, and threshold pressure gradient is the largest. The pores are well developed in sedimentary tuff reservoir, so the threshold 
pressure gradient is low. For volcanic rock reservoir and lowpermeability sandstone reservoir, there is little difference in pore throat radius, but volcanic rock reservoir has higher micropore content and worse connectivity, so the threshold pressure gradient of volcanic rock reservoir is slightly higher than that of low-permeability sandstone reservoir.

The fitting curves of threshold pressure gradient and permeability of four different kinds of lithological reservoirs are shown in Fig. 13. It can be seen from the figure that the correlation between threshold pressure gradient and permeability is well. The distribution of threshold pressure gradient of low-permeability sandstone and sedimentary tuff is relatively concentrated, which also confirms the conclusion that the homogeneity of pore structure of the two reservoirs is well. The volcanic reservoir is of poor homogeneity, and both large and small pores and throats are developed, so the distribution range of threshold pressure gradient is wide. When the permeability of shale reservoir is low, the development degree of nanopores is high, the corresponding threshold pressure gradient is also very high. When the permeability shale reservoir increases, the threshold gradient pressure decreases, but the value is still significantly higher than that of other reservoirs, indicating that the degree of micropores development is still high when the permeability of shale reservoir increases, and the reason for the increase of permeability is the gradual development of macropores in the reservoir.

The parameters of water permeability and pore throat radius calculated by nonlinear seepage test for four different reservoirs are shown in Table 7.

The permeability of four kinds of reservoirs measured by water is lower than that measured by gas, which is due to the greater surface effect of liquid in micropores, resulting in the decrease of permeability. The larger the permeability reduction rate is, the stronger the capillary force is and the more micropores are in the core. It can be seen from the results that the content of micropores in shale and volcanic rock is the most, followed by low-permeability sandstone, and the content of micropores in limestone reservoir is the least, which is basically consistent with the above conclusion of pore structure test.

For low-permeability sandstone reservoir and volcanic rock reservoir, the average pore throat radius values are basically the same, but according to the above analysis, there is a large difference in the content of micropores between them. On the one hand, the low-permeability sandstone and volcanic rocks have developed both large and small pore throats, and the difference between them mainly comes from the large and medium pore throats. There are more macropore throats in low-permeability sandstone reservoir, but larger macropore throats in volcanic rock reservoir, which leads to the similar calculated pore throat radius. On the other hand, because of the larger grain size of sandstone, the capillary force is larger; while volcanic rocks are formed by volcanic ash deposition, although more micropores are formed, the capillary force in the macropore space is smaller.

\section{Conclusion}

(1) The total number of pore throats at the nanoscale and submicron scale is mainly same for low-permeability sandstone reservoir, volcanic rock reservoir and shale reservoir. Micron throats take up a larger proportion in sedimentary tuff reservoir, which accounts for about $10 \%$ more than those in other kinds of lithological reservoirs. The amount of submicron throats in shale reservoir, volcanic rock reservoir and low-permeability sandstone reservoir increases in turn. The development difficulty for four different kinds of lithological reservoirs is decreased in the order of shale reservoir, volcanic rock reservoir, low-permeability sandstone reservoir and sedimentary tuff reservoir. The permeability contribution potential of four different kinds of lithological reservoirs is mainly distributed in submicron and micron pore throats. The micron and submicron pore throats in shale reservoir provide a low contribution of permeability and shale reservoir has lower development potential. The permeability contribution controlled by micron scale throats is increased in the order of volcanic rock reservoir, low-permeability sandstone reservoir and sedimentary tuff reservoir, and the development potential is increased.

(2) There are differences in pore structure among the four kinds of reservoirs in Western basins of China, which is closely related to the geological origin of them. Sedimentary tuff reservoir is formed by volcanic ash deposition. With the maturity of organic matter, the generated oil and gas are accumulated in a large number of micropores formed by volcanic ash denudation. Due to the lack of strong compaction in the process of reservoir formation, the reservoir space is dominated by large and medium-sized pores. Volcanic rock reservoir is mainly formed by volcanic lava overflow, which experienced strong weathering and leaching in the process of formation. Resulting in the development of both large and small pores in volcanic reservoir, the main reservoir space is dissolved pores and blowholes. Low-permeability sandstone reservoir is affected by anticline, back thrust and other surrounding conditions, the geological conditions are strong heterogeneity and more complex. At the same time, due to the invasion of the surrounding environment, there is a large amount of impurity in low-permeability sandstone reservoir, and the distribution is uneven, resulting in the complex development of pore space. For shale reservoir, the

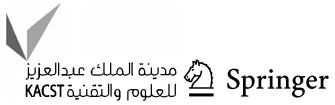


thickness of single layer inside the reservoir is thin, and changes of lithology are rapidly, which makes it difficult to form large pores inside. Pores between different layers are difficult to communicate to become an effective channel, resulting in the tight shale reservoir and poor physical properties. The effective seepage channel is provided by relatively developed interlayer fractures.

(3) There is a positive correlation between saturation of movable fluids and permeability of the four different kinds of lithological reservoirs. With the continuous increasing of permeability, the saturation of movable fluids can be increased from $15 \%$ to about $65 \%$. When the permeability is less than $0.5 \mathrm{mD}$, the saturation of movable fluids is decreased in the order of sedimentary tuff reservoir, volcanic rock reservoir, low-permeability sandstone reservoir and shale reservoir. When permeability is greater than $0.5 \mathrm{mD}$, the saturation of movable fluids is decreased in the order of sedimentary tuff reservoir, low-permeability sandstone reservoir, volcanic rock reservoir and shale reservoir.

(4) There is a good power function relationship between the threshold pressure gradient and the logarithm of permeability of the four different kinds of lithological reservoirs. With the increase of permeability, the threshold pressure gradient decreases. The effective development difficulty of four different kinds of lithological reservoirs is decreased in the order of shale reservoir, volcanic rock reservoir, low-permeability sandstone reservoir and sedimentary tuff reservoir. In addition, there is a good correlation between the threshold pressure gradient test results of the four different kinds of lithological reservoirs and their microscopic pore structures.

Funding This study was financially supported by the research and application of key technologies for continuous efficient and stable production of 50 million tons in Changqing Oilfield, Major scientific and technological project of China National Petroleum Corporation (Grant No. 2016E-0505). The funders had no role in study design, data collection and analysis, decision to publish, or preparation of the manuscript.

Open Access This article is licensed under a Creative Commons Attribution 4.0 International License, which permits use, sharing, adaptation, distribution and reproduction in any medium or format, as long as you give appropriate credit to the original author(s) and the source, provide a link to the Creative Commons licence, and indicate if changes were made. The images or other third party material in this article are included in the article's Creative Commons licence, unless indicated otherwise in a credit line to the material. If material is not included in the article's Creative Commons licence and your intended use is not permitted by statutory regulation or exceeds the permitted use, you will need to obtain permission directly from the copyright holder. To view a copy of this licence, visit http://creativecommons.org/licenses/by/4.0/.

\section{References}

Bin Z, Yanjun S (2012) Characterization of shale nanopore connectivity based on complex network theory. J Eng Geol 26(2):504-509

Cai J, Perfect E, Cheng C-L, Xiangyun Hu (2014) Generalized modeling of spontaneous imbibition based on Hagen-Poiseuille flow in tortuous capillaries with variably shaped apertures. Langmuir 30(18):5142-5151

Cai J, Luo L, Ye R, Zeng X, Xiangyun Hu (2015) Recent advances on fractal modeling of permeability for fibrous porous media. Fractals 23(1):1540006

Curtis ME, Ambrose RJ, Sonder CH et al (2011) Transmission and scanning electron microscopy investigation of pore connectivity of gas shales on the nanoscale [C] North American Unconventional Gas Conference and Exhibition. SPE, The Woodlands, TX, USA

Difei Z, Yinghai G, Xuan C et al (2018) Evaluation on shale pore network connectivity based on 3D printing, spontaneous permeability and low-field NMR - a case study of the Longmaxi formation shale reservoir in Sichuan basin. In: Proceedings of the meeting of palaeogeography professional committee

Feng Y, Zhengfu N, Changpeng H et al (2013) Micro-pore structure characteristics of shale reservoirs. Acta Pet Sin 34(2):301-311

Ghous A (2008) 3D imaging of reservoir core at multiple scales: correlations to petrophysical properties and pore scale fluid distributions. IPTC12767

Hao F, Cheng LS, Hassan O et al (2008) Threshold pressure gradient in ultra-low permeability reservoirs. Liq Fuels Technol 26(9):1024-1035

Hao-chuan L, Zheng-ming Y, Qian-hua X et al (2013) Study on new seepage flow model of tight oil reservoirs. Sci Technol Eng 13(26):7624-7628

Hong Z, Shuichang Z, Shaobo L et al (2014) Theoretical discussion and case analysis on the lower limit of tight oil filling hole throats. Pet Explor Dev 41(3):367-374

Hua T, Yong-chang Z, Shao-bo L et al (2012) Study on pore characteristics of organic rich shale by mercury penetration and gas adsorption method. Acta Pet Sin 3:419-427

Jianpeng Z, Li-Kai C, Hui C et al (2020) Quantitative characterization method of rock microstructure based on CT scanning digital cores. Geoscience. https://doi.org/10.19657/J.Geoscience.1000r 8527.2020.044

Keeler LM, Schuetz P, Erni R et al (2013) Characterization of multiscale microstructural features in Opalinus clay. Micro-porous Mesoporous Mater 170:83-94

Knackstedt MA (2006) 3D imaging and characterization of the pore space of carbonate core implications to single and two phase of properties. In: SPWLA 47th Annual Loin Symposium

Liang S, Xiaoqi W, Jin Xu et al (2016) Three-dimensional characterization and quantitative analysis on connectivity of micro-nano pore space. Pet Explor Dev 43(3):490-498

Likai C, Jianmeng S, Hong H et al (2019) Comprehensive evaluation on pore connectivity of carbonate reservoirs in Gaoshiti-Moxi block. J Xi ’an Univ Sci Technol 4:634-643 
Peng F (2009) Application of pore casting method in microscopic experimental study of pore structure in carbonate rocks. Mar Pet Geol 14(2):67-70

Ruizhong J, Li L, Xu J et al (2012) A new nonlinear seepage flow model and well test analysis for low permeability reservoirs. J Pet Sci 33(2):264-268

Shi Y, Yang M-M, Huang Y (2000) Study on the nonlinear seepage flow model of low permeability reservoirs. Acta Pet Sin 30(5):731-734

Tenshi X, Shuangfang L, Dazhi F et al (2019) Pore connectivity of high mature shale gas reservoirs of marine facies - a case study of Longmaxi formation in Pengshui area. Eval Dev Oil Gas Reserv $5: 45-53$

Tiening G, Zhengming Y, Haibo LI et al (2018) Structural characteristics of nano-pores in shale oil reservoirs. China Sci Technol Pap 21:2461-2467

Xiaodong H, Feifei A, Luo Y et al (2015) Special mesoscopic pore and fracture reservoir of Jurassic tight oil in Sichuan basin. Nat Gas Explor Dev 38(1):40-43

Xing Z, Yang S, Wen B et al (2013) experimental study on threshold pressure gradient of $\mathrm{CO}_{2}$ miscible flooding in low permeability reservoir. Pet Exp Geol 35(5):583-586

Xing H, Hui G, Liangbin D (2020) Micro pore structure and water displacement characteristics of tight sandstone reservoirs. J China Univ Pet (Nat Sci Ed) 44(01):80-88. https://doi.org/10.3969/j. issn.1673-5005.2020.01.009
Xuefen L (2015) Study on waterflooding characteristics and enhanced oil recovery in ultra-low permeability sandstone reservoirs. Southwest Petroleum University, Chengdu

Xuewu W, Zhengming Y, Haibo Li et al (2013) Study on microscopic residual oil distribution in ultra-low permeability reservoirs by NMR technology. J Appl Found Eng Sci 21(4):702-708

Yan-zhang H, Zheng-ming Y, Ying He et al (2013) Nonlinear seepage flow theory in low permeability porous media. Mech Pract 35(5): $1-8$

Ying D Er, Liu C (2001) Mathematical model for the rule of nonlinear seepage flows in low-permeability reservoirs and its application. Acta Pet Sin 22(4):72-77

Zhengming Y, Sheng M, Xiangui L et al (2007) Percentage parameter of moving fluid in ultra-low permeability reservoirs and its application. J Xi' an Pet Univ (Nat Sci Ed) 22(2):96-99

Zhidong Y, Menglou Z, Xin Z et al (2020) Reservoir characteristics and main controlling factors of volcanic rocks in Chepaizi Uplift, Junggar basin. J Yunnan Univ (Nat Sci Ed) 3:507-514

Publisher's Note Springer Nature remains neutral with regard to jurisdictional claims in published maps and institutional affiliations. 